\title{
Aesthetic Rehabilitation of the Teeth using Single Fixed Prostheses
}

\author{
AURELIANA CARAIANE ${ }^{1}$, VASILICA TOMA², GHEORGHE RAFTU1*, MIHAELA DEBITA ${ }^{3}$, ALINA-RAMONA DIMOFTE³, \\ CRISTINA IORDACHE \\ IUniversity of Medicine and Pharmacy Ovidius, 1 Universitatii Alley, 900470, Constanta, Romania \\ ${ }^{2}$ Grigore T. Popa University of Medicine and Pharmacy, Faculty of Dental Medicine, 16 Universitatii Str., 700115, Iasi, Romania \\ ${ }^{3}$ Dunarea de J os University of Galati, Faculty of Medicine and Pharmacy, 47 Domneasca Str., 800008, Galati, Romania
}

\begin{abstract}
Dental aesthetics has always been an integral part of practical dentistry despite the fact that only in the last decade ithas benefited from an objective critical analysis. Initially, aesthetics is regarded as an art- synonym for subjective, romantic and sentimental sensations. At a time when the basic aesthetic principles were based on Greek and Roman mathematics, the painters studied the aesthetics in order to create the painting, reflected in the depths of our soul. One can have an everlasting discussion about the two facets of dentalscientific and subjective aesthetics. It can be difficult to differentiate dental aesthetics from distinct units because all components are closely interrelated and interdependent. Complete and complex oro-dental treatments should be performed in such a way as to give back the patient both the masticatory functional skills, the feeling of comfortand the aesthetically lost aspect. The general trend in dental medicine focuses on replacing materials that, while meetingfunctional requirements, are not aesthetically pleasing. Thus, new generations of composite materials or integral ceramics take precedence over metal alloys used in dental treatments, from amalgam alloys to metal prosthetic restorations, including even gold ones. The database includes selection, examination and prosthetic resolution of 38 cases in the University of Galati University Prosthetic Clinic in the period 2016-2018. The possibility of creating unidirectional prostheses is a plus in the realization of true to nature works. Prosthetic variants, like dental faces, through which changes in shape, colour and even slight position can be made, with minimal invasiveness, or even non-invasive in the case of no-prep facets are a real advantage to aesthetics. From a biological point of view, the IPS e.max Press ceramic whole system is superior in that it is chemically inert, has a dental-like hardness, therefore it does not produce abrasion, the lack of metal avoids gingival changes colour, galvanic phenomena, and also a possibility of treatment for allergic persons in different components of the metal structure; the biocompatibility of these materials is clearly superior.
\end{abstract}

Keywords: aesthetics, oro-dental, prosthetic restorations, unidirectional prostheses

Through full ceramic restorations is meant the type of prosthetic restoration that is exclusively made of ceramics without a metallic infrastructure. Whole ceramic systems include all the clinical and laboratory techniques and procedures that make whole ceramic restorations. The success of the whole ceramic systems is also due to processes in the field of the development of the chemical initiation diacrilic cements and especially the dual-cure, which ensure a strong adhesion to the enamel- dentine/ ceramic interface. Also, dental adhesives have had an important role in the development of whole ceramic systems[1-3].

Nowadays, from various ceramic systems, various prosthetic reconstructions can be made: inlays, partial wreaths, envelope crowns, tensile bridges, dental implants, transfixation rods.

For ceramic masses without metallic infrastructure, it is very important that: the crystals be as small as possible, the quantity and density of crystals should be as high as possible; contain crystals arranged as homogeneously as possible to prevent crack propagation; the bond between the crystals or the vitreous phase is as strong as possible; to show as few micro-cracks, not only on the surface, but also on the mass of the material [4-6].

Advantages of fully ceramic systems: can highlight the desired colour shades; hardness close to dental hard tissues (does not cause abnormal teeth abrasion); itkeeps its colour in time; have an exceptional biocompatibility; have chromatic stability; low thermal conductivity; the allergic potential of certain metal alloy components is avoided; tissue tolerance due to the smooth and glossy appearance of glazed ceramics that do not favour adherence to the bacterial plaque;

The location of the boundary of the juxta and supra gingival preparation ensures: maintaining the integrity of tissues from the gingival trench; allows accurate fingerprinting; are checked, and can be adjusted as perfectly as possible; allows a cement check. Best for: facets, inlay, onlay, jacket crown, DCR, small tensile partial prosthesis (up to 3 elements in the front and premolar area) for adhesive bridges can be achieved[7-9] .

Disadvantages of whole ceramic systems: high sacrifice of dental substance; low fracture resistance; high cost; requires a special endowment of the laboratory.

Ceramic systems have a number of advantages: optimum aesthetics, excellent biocompatibility, low thermal conductivity, chemical stability.

Depending on the composition of the ceramics: feldspathic ceramics: first generation (metal scaffolding), of new generation - with leucitous content (for ceramic systems in total). Alumina ceramics: contains over $85 \%$ Al203 of which nuclei are made, then the ceramic platings are deposited. Vitreous glass (vitreous) - vitreoceramic made of fluorosilicator apatite crystals arranged irregularly in the glass mass [10-12].

Modern whole ceramic systems have a resistance comparable to metal-ceramics. Clinical studies have shown the appearance of cracks and fractures in the J acket 
crowns that have been cemented with conventional cements. These defects can be drastically reduced by fastening with diaprid cements.Using them involves a double gravage (with phosphoric acid for dental tissues and with hydrofluoric acid for ceramics), the application of dentin adhesives and silanizing agents. Whole ceramic systems have good biocompatibility. This is largely due to the stability of the bond between the component parts and the inorganic chemical composition of the ceramics, and the fact that the elimination of metallic components avoids the corrosion and galvanizing pheno mena. Aesthetics is incomparably better than those ofmetal-ceramic restorations.

The lack of metal in the construction of whole ceramic systems offers a great aesthetic advantage. The opacity and colour of the metal grit need notbe masked byceramic layers in contrast to the natural appearance. On the whole ceramic crowns besides this major advantage can also be added: smaller dental sacrifice-0.6-2 $\mathrm{mm}$; are lighter; have higher retentivity on the protector if they are cemented by adhesive technique; are chemically inert; there is no risk of the ceramic component being detached from the metal support; no gingival colour changes occur, if endodontic treatment is required, the access hole can be obturated with composite material. It is also necessary to mention the cases in which the metalceramic crowns can not be replaced with the whole ceramic ones, namely: bridges larger than an intermediate, bridges in the molar area, total bridges, bridges on the interstices, crowns on the teeth pillars that support retaining elements and stabilized for skeletal prostheses[13-15].

Ceramic materials used in dental medicine are considered to be highly biocompatible. Biocompatibility is generally known as a quality of materials to be compatible with the biological environment, tissues. The ability of the material to interact with body tissues without causing or causing minimal biological reactions. A material used in dental medicine is considered biocompatible if its functions and properties correspond to the biological environment without causing adverse responses.

Ceramic materials have always had a good reputation for biocompatibility, which has grown significantly over the last forty years. This upward trend can be attributed to the distinctive properties of these materials. Volatile substances are eliminated during the melting and synthesizing process used in the manufacture of ceramics. In addition, this degree of biocompatibility is given by properties such as: harmless ingredients: silicon, aluminum, sodium and potassium; low solubility, high stability in the oral environment, resistance to food and acid solutions; the reduced tendency to retain the bacterial plaque; have no adverse effects on interaction with other dental materials; does not decompose chemically, so it does not release products of the decomposition process. These ceramic materials are described as bioinert.

\section{Chemical Stability}

Dental materials are exposed to a wide range of $\mathrm{pH}$ and temperature values in the oral environment. Consequently, chemical stability is an essential requirement for any dental material.

The chemical durability according to ISO 687 (Ivoclar Vivadent AG, Schaan, 2005): IPS e.max Press: Chemical Solubility $\left[\mathrm{mg} / \mathrm{cm}^{2}\right]=40 \pm 10$; threshold value in accordance with the standard $\left[\mathrm{mg} / \mathrm{cm}^{2}\right]=<100$. The chemical solubility of IPS e.max Press is well below the limit value according to the standards.

\section{Cyclotoxicity}

Cyclotoxicity tests provide an indication of reactivity and tolerance of individual cells (mostly rodentfibroblasts) when exposed to soluble components of the dental material.

Therefore, the cytotoxicity itself was limited to validity to warn about to the biocompatibility of dental materials; cytotoxicity is sometimes detected in some tests, and in others not. If tests show a positive cytotoxic effect, additional, more elaborate tests for biocompatibility assessment are additionally performed. However, clinical experience can make a conclusive and meaningful assessment.In-vitro toxicity was tested at the NIOM Scandinavian Institute of Dental Material, Haslum (N), made by direct contact with cells. The test was conducted in accordance with ISO 10993-5: Biological evaluation of medical devices Part 5: Tests for vitro cytopoxicity[16-18].

This test did notreveal any statistical difference between individual ceramics. Cell viability increased from $80 \%$ in all tests performed on ceramics. Cells showed the same behaviour as untreated control cells. If a composite was used, a clear difference would have been noticed. Cell viability would have decreased by about $20 \%$, which means that composite materials are much more toxic than ceramics.

\section{Sensitivity, Irritations}

Cavazos and Allison have shown that dental ceramics, unlike other dental materials, do not induce any adverse reaction when they come in contact with the oral mucosa membrane. Mitchell, like Podshadley and Harrison, showed that glazed ceramics used in implant-based studies only caused very mild inflammatory reactions and had a much less irritating effect than other accepted dental materials such as gold and resin composites. As can practically exclude that ceramic materials cause direct inflammation in mucous membrane cells, possible irritation can generally be attributed to mechanical irritation.

Such reactions can normally be prevented by following the instructions for using IPS e.max Press. Compared to other materials, ceramics have a very low potential to cause irritation or sensitivity or even reaction reactions.

\section{Radioactivity}

Any concerns about possible radioactivity of ceramic materials have been removed. The main concerns are from the sixties, small particles of radioactive fluorescent substances have been introduced into various metalceramic systems. Therefore, possible levels of radiation have been measured in the relationship of ceramic materials in the oral cavity. Multiple ways of obtaining fluorescence of dental materials, have been discovered since the eighties. That is why we can assume that most of the manofacturists have stopped using radioactive ingredients in materials since then. However, a possible source of radioactivity can not be easily eliminated [1921].

Minor uranium and thorium impurities, which are sometimes used in the natural state or in pigments, are difficult to remove. Therefore, ceramic materials standards (EN ISO 6872, EN ISO 9693, ISO 13356) prohibit the use of additives and have stipulated the maximum allowed level of radioactivity in ceramic materials.

\section{The biological risk of exposed persons}

The dental technician is exposed to a higher risk potential (the risk for physicians is negligible) because ceramic materials are generally basic in the laboratory. The 
fine mineral sand that is formed along the technological process should not be inhaled. This potential for risk can be eliminated by using suction equipment and protective masks. If ceramics are used as indicated and appropriately, local or systemic side effects are very unlikely.Lithium silicate-based ceramics have been tested for any type of toxicological potential for use as a medial device.

The results show that the ceramic materials involved generally present a very low risk and offer a high degree of biocompatibility. Ceramic materials should therefore be preferred in dental applications. Based on current data and current levels of knowledge, IPS e.max Press can be said to have no toxic potential. If the material is applied in accordance with the manufacturer's instructions, it does not pose any risk to the health of patients, dental technicians or dentists.

Primary indications for ceramic restorations are improved aesthetics and a low cost price. Although physical properties and total ceramic crown resistance have been improved, no study has demonstrated that they can provide the same service area as metal restorations carefully crafted ceramics. Patients should use them if the aesthetics of restoration is more important than the longevity of the work.

The aesthetic potential of different ceramic systems is not the same. In case of restoring previous teeth, dental practitioners should use the most aesthetic system for which there is a well documented evidence of longevity. It is important to understand that simply introducing a ceramic restoration in exchange for a metal-ceramic restoration, will not guarantee a remarkable aesthetics. In order to achieve optimal aesthetics and adequate resistance, the dentist must bring a proper reduction to give the ceramic space the opportunity to create a restauration with excellent aesthetics, as well as the acquisition of the physiological contours of the crown.

The decision to use a ceramic restoration must be done in the context of a number of patient-related factors. In ideal circumstances involving unidental prior restorations, the investigator recommends that the dentist choose what he thinks is the best aesthetic option. In compromising or in the case of restoration of the posterior teeth or the placement of a partially fixed prosthesis, the dentist should choose a stronger zirconium system.

The advantages of a ceramic crown include: aesthetic appearance superior to all other techniques used, excellent translucency (similar to a vital natural tooth and excellent bio-compatibility). The absence of the metal-ceramic crown metal allows for a slightly more conservative reduction of amelo-dentinar tissue, although the oral area requires additional reduction to ensure retention of the restoration.

The ceramic crown is indicated in areas with an aesthetic standard where more conservative treatments would be inadequate. Typically, such a tooth has vestibular and proximal treated caries, but no longer correspond to their restoration with composite resins, the aesthetic requirements of the patient.

A pleasant dental appearance is given by the subjective appreciation of the nuance, shape and arrangement but also of their relationship with the gum, lips and face profile. It is not entirely easy to achieve the aesthetic harmony of patients, but it is the most important aspect of the treatment, and this is because our work is visible. To ensure success, accurate planning, critical assessment and flawless technical execution are required.

\section{Experimental part}

Material and method

Data base for the selection, examination and prosthetic resolution of 38 cases in the Clinic of Dental Prosthetics of the University Hospital Galap in the period 2016-2018.

The novelty of our study resides in the updating of the conservative methods of teeth with aesthetic and prosthetic importance with emphasizing the immediate prosthesis in maintaining the balance of the stomatognom system by morphological and functional restoration in order to prevent the complications due to altered oral health status.

\section{Results and discussions}

The special evolution of dental materials in the last decade obliges dental practitioners to increasingly use dental ceramics with increased translucency in clinical applications where there are high requirements and where the restaurant can colact on the dental surface.

A pleasant dental appearance is given by the subjective appreciation of the nuance, shape and arrangement but also of their relationship with the gum, lips and face profile. It is not entirely easy to achieve the aesthetic harmony of patients, but it is the most important aspect of treatment, and that is because our work is at sight.

In order to ensure success, precise planning, critical evaluation and a perfect technical execution are required. The aesthetic improvements in the front teeth are the most important and often represent the sole reason for restoring the rest.

The first and most important thing to achieve the success of the aesthetic result is to establish the nature of the patient's wishes, and this is done at the beginning of the treatment. One of the greatest challenges of dental practitioners performing crowns and physiognomy restorations is the need to equate expectations in terms of the technical and aesthetically achievable element.

\section{Conclusions}

Aesthetics is the major advantage that whole ceramic systems possess.

The IPS e.max Press system manages to provide a colourful variety that allows for perfect integration, with the optical effect truly impressive. The lack of metal, not only manages to minimize the sacrifice of substance, but offers restoration the possibility of achieving the camelionic effect, ceramic reflecting the hue of the dental substructures that surround them.

Even fully ceramic unidirectional crowns in comparison to metal substructure restorations can be considered less aggressive due to the need for less sacrifice.

Although they have a lower individual strength, this type of pressed ceramic works have increased strength and retention after cementation, if both work steps and cement preparation are strictly observed.

\section{References}

1.BRATU D. ROBERT NUSSBAUM, Bazele clinice oi tehnice ale protezãrii fixe Ed. A -Il-a Editura Medicalã Bucuresti 2005.

2.ION RANDASU, vol. I Proteze dentare, Ed. Medicalã, Bucure-ti 2000. 3.RANDASU, O.V. RANDASU, Materiale dentare, Ed. Medicala, Bucuresti 2001, Metalo Ceramica -Dentara; D.D.Slavescu, O.V.Rindasu, Editura RCR Print, Bucuresti 2001.

4.RIZKALLA A.S., JONES D.W., Mechanical properties of commercialhigh strength ceramic core materials.Dent Mater. 2004Feb.; 20(2):207-212. 
5.TASKONAK B., SERTGOZ A., Two-year clinical evaluation of lithiadisilicate-based all-ceramic crowns and fixed parial dentures.Dent Mater. 2006Nov; 22(11):1008-13.Epub.2005 Dec.20. 6.ANTOHE, M.E., AGOP FORNA, D., DASCALU,C.G., FORNA, N.C., The importance of observing the aesthetic requirements in partial edentulous rehabilitation - implications in medical-dental training, International Journal of education and information technologies Volume: 10 p. 199-203,2016

7.GRADINARU, I. , IGNAT, L., DASCALU, C.G., SOROAGA, L.V., ANTOHE,M.E., Studies regarding the architectural design of various composites and nanofibres used in dental medicine, Rev.Chim.(Bucharest),69, no.2,2018, p.328-331

8.ASAFTEI, I.V, SANDU,I.G., MIHAIL,L,ET AL, Conversion of ndustrial fedstock mainly with butanes and butenes over B-HZSM-5 and ZnHZSM-5 modifed catalysts, Rev.Chim.(Bucharest), 66, no.3,2015, p.336341

9.ANTOHE, M.E., AGOP FORNA, D., DASCALU, C.G., FORNA, N,C., Implications of digital image processing in the paraclinical assessment of the partially edentated patient, Rev.Chim.(Bucharest),69, no.2,2018 p.521-524

10.MATEI,M.N. , EARAR, K., TRINCA, L.C., Degradation characteristics of poly-tetrafluoroethylene coatings on stainlesssteel orthodontic wires immersed in tuna fish derived products, Rev. Chim. (Bucharest), 67, no.4, ,2016, pg.800-807

11.MATEI ,M.N., CHISCOP, I, EARAR, K., et al., Evaluation of corrosion resistance of $\mathrm{NiTi} \mathrm{Nb}$ orthodontic wires in tomato juice, Rev.Chim.(Bucharest),66, no.12,2015, p.2009-2012

12.MARECI, D., EARAR, K., ZETU, I., Comparative electrochemical behaviour, of uncoated and coated $\mathrm{Ni} \mathrm{Ti}$, for dental orthodontic wires, Mat.Plast., 52, no.2, 2015, p, 150-153
13.TARANU , T., CONSTANTIN, M.M., TOADER, M.P, et al., The benefits of using the lodine solution in the treatment of acne at pregnant women, Rev.Chim.(Bucharest),69, no.9, 2018, p.2343-2345

14.GRIGORE, M., FURNICA, C., ESANU, I., et al., Pentalogy of Cantrell associated with unilateral anophthalmia .Case reportand literature review, Medicine, 97(31),2018

15.ANCUTA ,C., POMIRLEANU, C., IORDACHE,C., et al., Serum lipid profile in diffuse versus limited systemic sclerosis data from the SASS cohort, Rev. Chim.(Bucharest),69, no.2,2018, p.403-406

16.BUDACU, C., NEMTOI, A., CONSTANTIN, M., Biomaterials used in Reduction and Fixation of Unstable Fractures of the Zygomaticomaxillary Complex, Mat. Plast., 54, no.4,2017, p.773-776 17.NEMTOI, A., DANILA, V., DRAGAN, E., ET AL., The Effects of Insulin and Strontium Ranelate on Guided Bone Regeneration in Diabetic Rats, 68(4), 2017,693-697

18.HABA, D., BUDACU. C., MIHAI. C., The Role of Chemical Substances in Classic and Modern Sialography Technique and applications, Rev.Chim.(Bucharest),68, no12, 2017, p.2829

19.NITESCU D., MIHAI C., OANTA C., Evaluation of Cumulative Effects of Chemotherapy and Bevacizumab (Avastin) in Oncological Patients with Periodontal Disease, Rev.Chim.(Bucharest),68, no.3,2017, p. 549 20.BELEI, D., FORNA, N.C., SANDU, I., Novel Mesoionic 2-Methy1-4(1,3-Dithiol-2-yllum)phenolates, Rev.Chim.(Bucharest), 65, no.1, 2014, pg.80-83

21.NICULESCU,O., NICA ,P., GURLUI, S., et al. , Experimental Investigations of Polymer Plasma Laser Ablation, Mat. Plast., 46, no.3, 2009, p.336-338

Manuscript received:19.08.2018 